\title{
GENTLE YOGA UNTUK KECEMASAN IBU HAMIL MENGHADAPI PERSALINAN
}

\author{
Gentle Yoga for Pregnant Mother's Anxiety Facing Labor
}

\author{
I Nyoman Suartha ${ }^{1}$, Made Ririn Sri Wulandari ${ }^{2}$, Ni Putu Muliantari Anggari Dewi ${ }^{3}$ \\ ${ }^{1}$ Program Studi S1 Keperawatan, Stikes Bina Usada Bali, Indonesia \\ ${ }^{2}$ Program Studi S1 Keperawatan, Stikes Bina Usada Bali, Indonesia \\ ${ }^{3}$ Program Studi S1 Keperawatan, Stikes Bina Usada Bali, Indonesia \\ Korespondensi: Made Ririn Sri Wulandaridan maderirinsw@gmail.com
}

\begin{abstract}
ABSTRAK
Latar Belakang: Masa kehamilan merupakan masa yang rentang terjadinya kecemasan pada ibu hamil. Kecemasan yang dirasakan ibu hamil berkaitan dengan diri sendiri dan bayi dalam kandungannya yang dipengaruhi oleh pengalaman pada kehamilan sebelumnya atau pertama kali mengalami persalinan. Tujuan Penelitian Adapun tujuan dari penelitian ini adalah untuk mengetahui pengaruh gentle yoga terhadap kecemasan pada ibu hamil dalam menghadapi persalinan di Puskesmas Penebel I. Metedologi: Desain penelitian ini menggunakan pre-eksperimen design dengan rancangan one group pretest-postest design. Populasi dalam penelitian ini adalah ibu hamil dengan teknik pengambilan sampel menggunakan non probability sampling dengan cara purposive sampling yang terdiri dari 36 responden. Instrumen pengumpulan data menggunakan kuesioner. Uji statistik yang digunakan yaitu wilcoxon signed rank-test. Hasil: Hasil penelitian yang didapatkan adalah nilai $\mathrm{p}$ value 0,001 yang berarti ada perbedaan yang signifikan antara kecemasan ibu hamil sebelum dan sesudah diberikan intervensi Gentle Yoga. Kesimpulan: Hasil penelitian ini dapat dijadikan bahan untuk pengembangan ilmu keperawatan sehingga dapat mengurangi kecemasan pada ibu hamil melalui metode non farmakologi.
\end{abstract}

Kata Kunci: Kecemasan; Ibu Hamil; Gentle Yoga.

\section{ABSTRACT}

Background: Pregnancy is a period that is prone to anxiety in pregnant women. The anxiety that is felt by pregnant women is related to themselves and their womb babies which are influenced by experience in the previous or first pregnancy. Objectives: The purpose of this study was to find out the effect of Gentle Yoga on anxiety experienced by pregnant women facing labor in Penebel I Public Health Center. Methodology: The design of this study used a pre-experimental design with a one group pretest-posttest design. The population in this study were pregnant women with a sampling technique using non-probability sampling by purposive sampling consisting of 36 respondents. The data collection instrument used a questionnaire. The statistical test used was the Wilcoxon signed rank-test. Result: The results obtained were p value 0.001 which means there is a significant difference between the anxiety of pregnant women before and after being given the Gentle Yoga intervention. Conclusions: The results of this study can be used as material for the development of nursing science so that it can reduce anxiety in pregnant women through non-pharmacological methods.

Keywords: Anxiety; Pregnant Women; Gentle Yoga. 


\section{PENDAHULUAN}

Masa kehamilan merupakan masa yang rentang terjadinya kecemasan pada ibu hamil. Pada masa kehamilan seorang ibu hamil mengalami perubahan fisik dan perubahan psikologis akibat peningkatan hormon kehamilan. Ibu hamil mengalami perubahan yang signifikan pada fungsi fisiologis dan psikologis, proses penyesuaian diri terhadap keadaan baru ini seringkali menimbulkan kecemasan. Perubahan secara fisik pada ibu hamil seperti perubahan bentuk tubuh dengan badan yang semakin membesar, munculnya jerawat di wajah atau kulit muka yang mengelupas. Perubahan psikologis yang terjadi pada ibu hamil antara lain disebabkan karena rasa cemas menjelang kelahiran, konsentrasi tentang perubahan hubungan dengan pasangan, serta rasa cemas pada masalah keuangan (Hariyanto, 2015).

Berdasarkan penelitian yang dilakukan di Amerika Tengah Nicaragua $41 \%$ wanita hamil memiliki gejala kecemasan dan $57 \%$ wanita hamil mengalami depresi (Verbeek, 2015). Di Indonesia terdapat 373.000 .000 orang ibu hamil yang mengalami kecemasan dalam menghadapi persalinan ada sebanyak 107.000 .000 orang $(28,7 \%)$. Dampak buruk yang terjadi pada ibu hamil akibat mengalami kecemasan yaitu preeklampsi dan prematur. Akibat tersebut dapat meningkatkan Angka Kematian Ibu (AKI) dan Bayi dengan Berat Badan Lahir Rendah (BBLR). Data di Bali pada tahun 2012 menunjukkan, jumlah kematian ibu hamil masih ada yaitu sebesar 28,83\% (Diani, 2013).

Kecemasan pada ibu hamil adalah kecemasan yang dirasakan ibu hamil yang berkaitan dengan diri sendiri dan bayi dalam kandungannya yang dipengaruhi oleh pengalaman pada kehamilan sebelumnya, sementara itu pada ibu primigravida sering memiliki pikiran yang mengganggu, sebagai pengembangan reaksi kecemasan terhadap cerita yang diperolehnya. Oleh karena itu, muncul ketakutan-ketakutan pada ibu primigravida yang belum memiliki pengalaman bersalin. Ibu hamil menjadi mudah marah atau tersinggung, gelisah, dan tidak mampu memusatkan perhatian (Handayani, 2015).

Pada umumnya wanita yang sedang hamil takut menghadapi proses persalinan karena rasa sakit yang menimbulkan rasa takut dan cemas. Hal ini dapat menimbulkan ketegangan jiwa dan fisik yang akan mengakibatkan kakunya otot-otot dan persendian yang tidak wajar. Stres atau kecemasan tersebut terkait dengan berbagai hasil kehamilan, rasa sakit dan keluhan somatik lain yang sering terjadi dengan gangguan mood pada ibu hamil (Jannah, 2018).

Berdasarkan hasil studi pendahuluan yang dilakukan pada tanggal 20 Agustus 2019 didapatkan jumlah data di Puskesmas Penebel I sebanyak 40 ibu hamil, diantaranya dari 10 terdapat $7 \mathrm{ibu}$ hamil yang mengalami kecemasan yang ditandai dengan perasaan gelisah, mudah marah, kesulitan dalam membuat keputusan dan mengalami perubahan nafsu makan. Hal tersebut sangat mengganggu ibu hamil selama masa kehamilan karena sulit untuk diatasi. Berdasarkan fenomena yang ada, penelitian tentang pengaruh gentle yoga terhadap kecemasan ibu hamil perlu dilakukan.

\section{TUJUAN PENELITIAN}

Mengidentifikasi

tingkat pengetahuan ibu nifas tentang fisiologi laktasi di Ruang Nifas Rumah Sakit Umum Bangli Tahun 2021. 


\section{METODE PENELITIAN}

Penelitian ini merupakan penelitian kuantitatif pre eksperimental dengan one-group pre test-post test designs. Penelitian ini dilaksanakan di Puskesmas Penebel I. Populasi dalam penelitian ini adalah 40 ibu hamil yang memeriksakan kehamilan dan mengalami kecemasan di Puskesmas Penebel I. Penentuan sampel menggunakan teknik sampling jenis nonprobability yaitu purposive sampling. Dengan kriteria inklusi ; Ibu hamil yang memeriksakan kehamilannya di Puskesmas Penebel I, Pasien belum pernah mendapatkan atau melakukan gentle yoga, Mengerti pertanyaan yang diajukan pada lembar kuesioner (bisa baca dan tulis berbahasa Indonesia). Kriteria Ekslusi; Pasien menolak menjadi responden, Ibu hamil yang mengalami komplikasi kehamilan seperti pendarahan dan tidak mengalami cacat fisik, didapatkan jumlah sample 36 responden.

Analisa data terdiri dari univariat dan bivariat. Analisis univariat yang akan diteliti adalah karakteristik subjek penelitian berdasarkan usia, trimester kehamilan, pendidikan, pekerjaan, penghasilan dan mengenai tingkat kecemasan pada subjek penelitian sebelum dan sesudah diberikan gentle yoga. Analisa bivariat untuk mengetahui adanya pengaruh gentle yoga terhadap kecemasan pada ibu hamil dalam menghadapi persalinan adalah dengan menggunakan non parametric yaitu wilcoxon match pairs test, karena data tingkat kecemasan merupakan data ordinal sehingga uji yang tepat untuk data tersebut adalah pre test dan post test.

Pelaksanaan penelitian yang dilakukan peneliti berdasarkan atas review dan persetujuan dari tim ethical clearance STIKES Bina Usada Bali dan mendapatkan ijin dari Kepala
Puskesmas Penebel I untuk mengambil responden dari wilayah kerja Puskesmas Penebel I. Semua pasien yang menjadi responden penelitian mendapatkan lembar persetujuan (informed consent) sebelum terlibat dalam penelitian ini. Peneliti menjelaskan bahwa penelitian ini bersifat sukarela, dan semua pasien yang menjadi responden mendapatkan penjelasan mengenai manfaat, prosedur penelitian, serta jaminan kerahasiaan identitas data responden yang hanya digunakan untuk kepentingan penelitian.

\section{HASIL PENELITIAN}

Berdasarkan pengumpulan data dan analisis data, peneliti menyajikan data hasil dari karakteristik responden berdasarkan usia responden, pendidikan, pekerjaan, penghasilan serta trimester kehamilan pada ibu hamil di Puskesmas Penebel I.

Tabel 1. Hasil Karakteristik Responden

\begin{tabular}{|c|c|c|}
\hline \multirow{2}{*}{$\begin{array}{c}\text { Karakteristik } \\
\text { Responden }\end{array}$} & \multicolumn{2}{|l|}{$\mathbf{N}=\mathbf{3 6}$} \\
\hline & n (\%) & $\begin{array}{l}\text { Mean } \pm \\
\text { SD }\end{array}$ \\
\hline 1. Umur & & $\begin{array}{c}27,89 \pm \\
3,302\end{array}$ \\
\hline 2. Pendidikan & & \\
\hline$-\mathrm{SD}$ & $4(11,1)$ & \\
\hline - SMP & $5(13,9)$ & \\
\hline - SMA & $18(50,0)$ & \\
\hline $\begin{array}{l}\text { - Universitas/Ak } \\
\text { ademik }\end{array}$ & $9(25,0)$ & \\
\hline 3. Pekerjaan & & \\
\hline - PNS & $4(11,1)$ & \\
\hline - Wiraswasta & $14(38,9)$ & \\
\hline 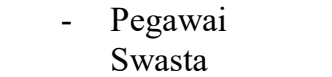 & $6(16,7)$ & \\
\hline - IRT & $12(33,3)$ & \\
\hline 4. Penghasilan & & \\
\hline $\begin{array}{l}-\quad<\mathrm{Rp} . \\
\quad 2.239 .500\end{array}$ & $22(61,1)$ & \\
\hline $\begin{array}{l}-\quad \text { Rp. } 2.239 .500 \\
\quad \text {-Rp.3.000.000 }\end{array}$ & $10(27,8)$ & \\
\hline $\begin{array}{l}\text { - Rp. } 3.000 .000 \\
\text {-Rp. }\end{array}$ & $4(11,1)$ & \\
\hline
\end{tabular}




\subsection{0 .000}

5. Trimester

Kehamilan

\begin{tabular}{clc}
- & Trimester I & $5(13,9)$ \\
$-\quad$ & Trimester II & $6(16,7)$ \\
- & Trimester III & $25(69,4)$ \\
\hline \multicolumn{2}{l}{ Sumber: Data Primer }
\end{tabular}

Tabel 1 distribusi frekuensi responden berdasarkan umur menunjukan bahwa rata rata umur responden yaitu 27,89 tahun dengan usia tertinggi yaitu 33 tahun dan terendah 22 tahun. Karakteristik subjek penelitian berdasarkan riwayat pendidikan bahwa mayoritas responden memiliki riwayat pendidikan pada jenjang SMA yaitu sebanyak 18 orang dengan persentase 50,0\%. Pada penelitian ini karakteristik subjek penelitian berdasarkan pekerjaan menunjukkan bahwa mayoritas responden memiliki pekerjaan sebagai wiraswasta yaitu sebanyak 14 orang dengan persentase 38,9\%. Berdasarkan penghasilan responden menunjukkan bahwa mayoritas responden memiliki penghasilan pada kategori $<\mathrm{Rp}$. 2.239.500 yaitu sebanyak 22 orang dengan persentase $61,1 \%$. Sedangkan berdasarkan trimester kehamilan karakteristik responden menunjukkan bahwa mayoritas trimester kehamilan responden yaitu trimester III yaitu sebanyak 25 orang dengan persentase $(69,4 \%)$.

Hasil analisis univariat dan bivariat yang menjelaskan tentang tingkat kecemasan pada ibu hamil sebelum dan sesudah intervensi dan hasil analisis uji statistik wilcoxon signed rank test untuk menganalisis pengaruh gentle yoga terhadap kecemasan pada ibu hamil dalam menghadapi persalinan. Hasil analisis disajikan dalam bentuk tabel sebagai berikut:
Tabel 2. Tingkat kecemasan pada ibu hamil di Puskemas

Penebel I

\begin{tabular}{|c|c|c|c|c|c|}
\hline \multirow[t]{2}{*}{ Kategori } & $\begin{array}{c}\text { Pre } \\
N=36\end{array}$ & $\begin{array}{c}\text { Post } \\
\mathbf{N}=36\end{array}$ & \multirow[t]{2}{*}{ Selisih } & \multirow[t]{2}{*}{$\begin{array}{c}p \\
\text { value }\end{array}$} & \multirow[t]{2}{*}{$\mathbf{Z}$} \\
\hline & n (\%) & n (\%) & & & \\
\hline $\begin{array}{l}\text { Tidak } \\
\text { cemas }\end{array}$ & $\begin{array}{c}4 \\
(11,1)\end{array}$ & $\begin{array}{c}10 \\
(27,8)\end{array}$ & 6 & \multirow{5}{*}{0,001} & \multirow{5}{*}{$\begin{array}{c}- \\
3 \\
18 \\
8\end{array}$} \\
\hline $\begin{array}{l}\text { Kecemasan } \\
\text { ringan }\end{array}$ & $\begin{array}{c}10 \\
(27,8)\end{array}$ & $\begin{array}{c}15 \\
(41,7)\end{array}$ & 5 & & \\
\hline $\begin{array}{l}\text { Kecemasan } \\
\text { sedang }\end{array}$ & $\begin{array}{c}13 \\
(36,1)\end{array}$ & $\begin{array}{c}7 \\
(19,4)\end{array}$ & 6 & & \\
\hline $\begin{array}{l}\text { Kecemasan } \\
\text { berat }\end{array}$ & $\begin{array}{c}9 \\
(25,0)\end{array}$ & $\begin{array}{c}4 \\
(11,1)\end{array}$ & 5 & & \\
\hline $\begin{array}{l}\text { Kecemasan } \\
\text { berat sekali }\end{array}$ & $0(0)$ & $0(0)$ & 0 & & \\
\hline
\end{tabular}

Sumber: Data Primer

Tabel 2 menunjukkan bahwa kecemasan pada ibu hamil sebelum diberikan gentle yoga sebagian besar berada pada kategori sedang yaitu sebanyak 13 orang dengan persentase $36,1 \%$ dan kecemasan pada ibu hamil setelah diberikan gentle yoga sebagian besar berada pada kategori ringan yaitu sebanyak 15 orang dengan persentase $41,7 \%$. Terdapat perbedaan nilai responden sebelum dan sesudah diberikan intervensi gentle yoga dengan memperoleh $p$ value 0,001 yang berarti $p$ value $\leq 0,05$ dan secara klinis ditemukan selisih antara nilai responden sebelum dan sesudah diberikan intervensi gentle yoga sehingga ada perbedaan yang signifikan antara kecemasan pada ibu hamil sebelum dan sesudah diberikan intervensi gentle yoga di Puskesmas Penebel I dengan nilai $\mathrm{z}$ hitung $=3,188$ dan $\mathrm{z}$ tabel $=1,96$ berarti $\mathrm{z}$ hitung lebih besar dari pada $\mathrm{z}$ tabel yang artinya Ho ditolak $\mathrm{Ha}$ diterima. Jadi dapat disimpulkan bahwa ada pengaruh secara signifikan antara kecemasan pada ibu hamil dalam menghadapi persalinan sebelum dan sesudah diberikan intervensi gentle yoga di Puskesmas Penebel I. 


\section{PEMBAHASAN}

\section{Tingkat Kecemasan Pada Ibu Hamil Sebelum Diberikan Latihan Gentle Yoga}

Hasil penelitian menunjukkan bahwa tingkat kecemasan responden sebelum diberikan latihan Gentle Yoga sebagian besar memiliki tingkat kecemasan sedang, yaitu sebanyak 13 orang dengan persentase $36,1 \%$. Kecemasan merupakan suatu pengalaman subjektif mengenai ketegangan mental yang menggelisahkan sebagai reaksi umum dan ketidakmampuan menghadapi masalah atau adanya rasa aman. Kecemasan ibu hamil disebabkan karena masa panjang saat menanti kelahiran penuh ketidakpastian. Selain itu bayangan tentang hal-hal yang menakutkan saat proses persalinan walaupun yang dibayangkannya belum tentu terjadi. Situasi ini menimbulkan perubahan drastis, bukan hanya fisik tetapi juga psikologis (Aswitami, 2017).

Pieter dan Lubis (2010) menjelaskan bahwa ibu hamil akan mengalami bentuk-bentuk perubahan psikis yaitu perubahan emosional, cenderung malas, sensitif, gampang cemburu, minta perhatian lebih, perasaan tidak nyaman, depresi, stress, dan mengalami kecemasan. Ibu hamil cenderung mengalami kecemasan yang diikuti dengan perasaan nyeri. Sistem endokrin yang terdiri dari kelenjar adrenal, tiroid, dan pituitary (pusat pengendalian kelenjar) melepaskan pengeluaran hormon ke aliran darah. Hal ini menyebabkan sistem syaraf otonom mengaktifkan kelenjar adrenal yang mempengaruhi sistem hormon epinefrin. Peningkatan hormon adrenalin dan noradrenalin atau epinefrin dan norepinefrin menimbulkan disregulasi biokimia tubuh, sehingga muncul ketegangan fisik pada diri ibu hamil yang membuat ibu hamil menjadi mudah marah atau tersinggung, gelisah, tidak mampu memusatkan perhatian, ragu-ragu, bahkan kemungkinan ingin lari dari kenyataan hidup. Pada gilirannya, kondisi ini dapat menyebabkan kecemasan dan ketegangan lebih lanjut sehingga membentuk suatu siklus umpan balik yang dapat meningkatkan intensitas emosional secara keseluruhan (Hawari, 2011).

Hal tersebut didukung oleh karakteristik responden pada penelitian ini berdasarkan pekerjaan, pada penelitian ini status pekerjaan responden tertinggi yaitu wiraswasta sebanyak 14 orang. Hasil ini sejalan dengan penelitian yang dilakukan oleh Retnaningsih (2018) yaitu persentase tertinggi adalah ibu hamil yang bekerja sebanyak 8 orang ibu hamil (57.2\%). Menurut Effendi (2009) pekerjaan ibu dapat mempengaruhi kecemasan karena adanya tekanan dan berbagai stresor ditempat pekerjaan. Beban kerja yang terlalu berat atau kemampuan fisik yang terlalu lemah dapat mengakibatkan seorang ibu hamil yang bekerja mengalami gangguan atau penyakit akibat kerja, seperti kondisi lingkungan.

Selain karakteristik responden berdasarkan pekerjaan, kecemasan pada ibu hamil didukung dengan karakteristik responden berdasarkan trimester kehamilan, pada penelitian ini mayoritas responden yaitu trimester III sebanyak 25 orang. Hasil ini sependapat dengan Retnaningsih (2016) yang mengatakan bahwa sebagian besar dari ibu hamil trimester III mengalami kecemasan dalam menghadapi persalinan. Saat usia kehamilan menjelang persalinan maka akan muncul pertanyaan dan bayangan seperti persalinan yang tidak lancar, cara mengejan, kejadian yang terjadi saat melahirkan, atau keadaan bayi pada 
saat lahir, akan semakin sering muncul dalam benak ibu hamil. Rasa nyeri pada saat persalinan sudah sejak dulu menjadi pokok pembicaraan para wanita (Hasuki,2010).

Terkait dengan hasil temuan pada penelitian ini mengenai tingkat kecemasan pada ibu hamil sebelum diberikan intervensi, dari hasil analisis didapatkan bahwa kecemasan pada ibu hamil dialami oleh ibu hamil yang masih bekerja karena pada ibu hamil yang bekerja akan lebih mengalami tekanan dan berbagai stresor ditempat pekerjaan. Selain itu kecemasan pada ibu hamil lebih cenderung dialami oleh ibu hamil trimester III disebabkan karena saat usia kehamilan menjelang persalinan maka akan muncul pertanyaan dan bayangan tentang persalinannya sehingga hal tersebut akan membuat ibu hamil mengalami kecemasan.

\section{Tingkat Kecemasan Pada Ibu Hamil Sesudah Diberikan Latihan Gentle Yoga}

Hasil penelitian mengenai kecemasan pada ibu hamil setelah intervensi menunjukkan bahwa kecemasan pada ibu hamil setelah diberikan intervensi gentle yoga mayoritas ibu hamil berada pada kategori cemas ringan yaitu sebanyak 15 orang dengan persentase $41,7 \%$. hasil penelitian ini didukung oleh karakteristik responden dalam penelitian ini berdasarkan umur responden yaitu rata-rata 28 tahun, hal ini sejalan dengan penelitian yang dilakukan oleh Wulandari (2016) yaitu rata-rata usia kehamilan ibu hamil 28 tahun. Menurut Zamriati (2013), usia terkait dengan kesiapan fisik dan psikis ibu. Usia 20-35 tahun dianggap usia paling aman untuk menjalani kehamilan dan persalinan.

Penurunan kecemasan setelah diberikan intervensi didukung juga oleh karakteristik responden berdasarkan pendidikan, tingkat pendidikan tertinggi pada penelitian ini adalah SMA sebanyak 18 orang dan universitas/akademik sebanyak 9 orang. Penelitian ini sejalan dengan penelitian yang dilakukan oleh Mayasari (2018) yaitu ibu hamil berpendidikan tinggi lulusan SMA, DIII, DIV, S1, S2 sebanyak 53 orang mengalami kecemasan ringan. Tingkat pendidikan dapat mempengaruhi tingkat pengetahuan responden oleh karena kemampuan seseorang dalam menerima dan memahami ditentukan oleh tingkat pendidikan yang dimiliki. Penerimaan dan pemahaman terhadap informasi yang diterima seseorang yang berpendidikan tinggi lebih baik dibandingkan dengan seseorang yang berpendidikan rendah (Corneles, 2015). Menurut Walangadi (2014) pengetahuan akan menentukan dan mempengaruhi sikap seseorang dalam menghadapi persalinan. Pengetahuan tentang persalinan mempunyai peranan penting dengan hubungan persiapan ibu hamil dalam menghadapi persalinan nantinya, sehingga ibu tidak merasa cemas dan dapat menikmati proses persalinan. Ibu hamil yang memiliki pengetahuan yang tinggi dengan tingkat pendidikan yang lebih tinggi bisa mengatasi kehamilannya dengan baik bila dibandingkan yang tidak memiliki pengetahuan dengan tingkat pendidikan yang rendah.

Terkait dengan hasil temuan pada penelitian ini mengenai tingkat kecemasan pada ibu hamil setelah diberikan intervensi, terdapat penurunan pada kecemasan. Dari hasil analisis setelah diberikan intervensi, ibu hamil mengalami penurunan kecemasan karena sebagian besar responden memiliki pendidikan tertinggi yaitu SMA dan Universitas/akademik. Tingkat pendidikan yang tinggi akan 
mempermudah ibu hamil untuk menerima dan memahami informasi tentang persalinan sehingga ibu dapat mengatasi kecemasan yang dirasakan.

\section{Hasil Analisa Pengaruh Gentle Yoga Terhadap Kecemasan Ibu Hamil}

Hasil analisis mengenai pengaruh gentle yoga terhadap kecemasan pada ibu hamil dalam menghadapi persalinan menunjukkan bahwa terdapat perbedaan nilai responden sebelum dan sesudah diberikan intervensi gentle yoga dengan memperoleh $p$ value 0,001 yang berarti $\mathrm{p}$ value $\leq 0,05$ sehingga ada perbedaan yang signifikan antara kecemasan pada ibu hamil sebelum dan sesudah diberikan intervensi gentle yoga. Kecemasan pada ibu hamil akan berpengaruh terhadap pertumbuhan dan perkembangan janin. Ibu yang mengalami kecemasan akan berdampak negative pula pada kesehatan dan keselamatan janin dan ibu yang mengandungnya. Oleh karena itu, ketika ibu menjalani masa kehamilan sampai menjelang persalinan, membutuhkan ketenangan agar tidak mengalami kecemasan yang berlebih sehingga proses persalinan menjadi lancer (Apriliani, 2015). Latihan fisik dalam kehamilan bisa digunakan sebagai sarana untuk mengurangi stress pada ibu hamil yang aman dan bermanfaat bagi kesehatan.

Latihan Gentle Yoga adalah sebuah treatmen fisik yang ternyata juga dapat memberikan efek psikologis karena memberikan efek relaksasi pada tubuh seseorang dan mempengaruhi beberapa aspek psikologis pada seseorang yang melakukannya dikatakan dapat membantu menurunkan kecemasan (Aprilia, 2014). Gentle Yoga dapat membantu ibu hamil mengendalikan pikiran, keinginan, dan reaksi terhadap stres. Gentle Yoga terdiri dari beberapa bagian diantaranya relaksasi, mengatur postur, dan olah napas.

Secara fisiologis, pada saat melakukan gerakan yoga, secara langsung hipotalamus akan mempengaruhi sistem saraf otonom yaitu menurunkan aktivitas saraf simpatis dan meningkatkan aktivitas saraf parasimpatis. Yoga akan menghambat peningkatan saraf simpatis sehingga hormon penyebab disregulasi tubuh dapat dikurangi jumlahnya (Streeter, 2012). Hal ini sejalan dengan penelitian yang dilakukan oleh Apriliani (2015) menjelaskan bahwa yoga berguna untuk mengoptimalkan keseimbangan fisik, memelihara kesehatan kehamilan, menghilangkan keluhan yang kejadi karena perubahanperubahan akibat proses kehamilan dan memepermudah proses persalinan. Yoga akan membuat serotonin sebagai hormone tenang meningkat dan endorphin sebagai hormon gembira meningkat.

Penelitian yang dilakukan oleh Aryani, Handayani \& Susilowati (2018) yang menjelaskan bahwa ada pengaruh pelaksanaan gentle yoga terhadap kecemasan menjelang persalinan pada ibu hamil primigravida Trimester III di Klinik Bidan Kita Klaten dengan nilai $\mathrm{p}$-value $=0,000$. Di dukung juga oleh penelitian yang dilakukan oleh Aswitami (2017) mengenai pengaruh yoga antenatal terhadap tingkat kecemasan pada ibu hamil dalam menghadapi proses persalinan di klinik yayasan bumi sehat $(p$-value $=0,000)$ yang menjelaskan bahwa setelah diberikan yoga, sebagian besar kecemasan responden berada pada kategori ringan yaitu sebanyak 14 orang (40,0\%).

Berdasarkan dari hasil analisis didapatkan bahwa ada pengaruh gentle yoga terhadap kecemasan pada ibu 
hamil dalam menghadapi persalinan di Puskesmas Penebel I. Gentle Yoga dapat memberikan efek psikologis karena memberikan efek relaksasi terhadap tubuh seseorang sehingga ketika melakukan gerakan yoga ibu hamil akan merasa nyaman dan tenang.

\section{KESIMPULAN}

Hasil penelitian ini dapat disimpulkan bahwa gentle yoga dapat menurunkan kecemasan yang dari tingkat sedang ke tingkat ringan sehingga sangat membantu menurunkan kecemasan pada ibu hamil menjelang atau menghadapi persalinannya.

Penelitian ini dapat dijadikan acuan bagi layanan keperawatan untuk dapat memberikan dan menerapkan program gentle yoga dalam proses keperawatan pada ibu hamil guna mengurangi kecemasan yang dialami oleh ibu hamil semasa kehamilan hingga proses persalinan, terutama menjadi program unggulan dalam senam ibu hamil di Puskesmas.

\section{DAFTAR PUSTAKA}

Annisa, D \& Ifdil, I. (2016). Konsep kecemasan (anxiety) pada lanjut usia (lansia). Konselor, 2016, 5.2: 93-99.

Annisa, S. (2011). Faktor-faktor risiko persalinan sectio caesaria di RSUD Dr. Adjidarmo Lebak Pada Bulan Oktober-Desember 2010. Publikasi Skripsi Sarjana Kedokteran Universitas Islam Negeri Syarif Hidayatullah Jakarta.

Aprilia,Yesie. (2014). Gentle birth balance. Mizan: Bandung

Apriliani, R.A. (2015). Pengaruh yoga prenatal tehadapkecemasan sesaat dalam menghadapi persalinan pada primigravida trimester III di galenia mom and baby center kota Bandung.
Bandung: Fakultas Psikologi, Universitas Islam

Aprillia, Y. (2017). Bebas takut hamil dan melahirkan. Gramedia: Pustaka Utama.

Arikunto, S. (2013). Prosedur penelitian: Suatu pendekatan praktik. Jakarta: Rineka Cipta.

Aryani, R. Z., Handayani, R., \& Susilowati, D. (2018). Pengaruh pelaksanaan gentle yoga terhadap kecemasan menjelang persalinan pada ibu hamil primigravida trimester III di klinik bidan kita Klaten. Jurnal Kebidanan Dan Kesehatan Tradisional, 3(2).

Aswitami, N. G. A. P. (2017). Pengaruh yoga antenatal terhadap tingkat kecemasan pada ibu hamil TW III dalam menghadapi proses persalinan di Klinik Yayasan Bumi Sehat. Jurnal Kesehatan Terpadu, 1(1).

Departemen Kesehatan RI. (2008). Profil kesehatan Indonesia. Jakarta: Depkes RI Jakarta.

Dewi \& Sunarsih. (2014). Asuhan kehamilan untuk kebidanan. Jakarta: Salemba Medika.

Effendi, F.M. (2009). Keperawatan kesehatan komunitas: teori dan praktik dalam keperawatan. Jakarta. Salemba Medika

Ernawati, N \& Hernowo, D. (2016). Pengaruh pemberian pendidikan kesehatan tentang proses persalinan terhadap tingkat kecemasan ibu primigravida Trimester III. Jurnal Kesehatan Hesti Wira Sakti, 3(2), 45-40.

Fazdria, F \& Harahap, S. (2016). Gambaran tingkat kecemasan pada ibu hamil dalam menghadapi persalinan di Desa Tualang Teungoh Kecamatan Langsa Kota Kabupaten Kota Langsa Tahun 2014. Jurnal 
Kedokteran Syiah Kuala, 16(1), 6-3.

Gupta, N. (2013). A systematic review of yoga for state anxiety: Consideration for occupational therapy. Canadian Journal Of Occupational Therapy.

Handayani, Reska. (2015). Faktorfaktor yang berhubungan dengan tingkat kecemasan menjelang persalinan pada ibu primigravida trismester III di wilayah kerja Puskesmas Lubuk Buaya Padang. Ners Jurnal Keperawatan, 11(1), 60-69.

Hariyanto. (2015). Implementasi belajar \& pembelajaran. Bandung: Remaja Rosdakarya.

Hasuki, I. (2010). Buku saku perawatan kesehatan ibu dan anak. EGC: Jakarta.

Hidayat, A.A.. (2014). Metode penelitian keperawatan dan teknis analisis data. Jakarta : Salemba Medika.

Husein, Umar. (2008). Metode penelitian untuk skripsi dan tesis bisnis. Jakarta: PT Rajagrafindo Persada.

Jannah, Khairiatul. (2018). Pengaruh senam yoga terhadap kesiapan fisik dan psikologis dalam menghadapi persalinan di BPM Lasmitasari, S.ST. Jurnal Kedokteran dan Kesehatan, Vol. 14, No. 1, Januari 2018.

Karina, W. F. (2017). Gambaran tingkat kecemasan ibu hamil trimester III dalam menghadapi persalinan di Puskesmas Kretek Bantul.

Lestari, T. (2015). Analisis faktor yang berhubungan dengan tingkat kecemasan. Jurnal Penelitian. Surabaya: Unair.

Machmudah, T. (2010). Pengaruh Persalinan Dengan Komplikasi Terhadap Kemungkinan Terjadinya Postpartum Blues Di
Kota Semarang. Tesis

Universitas Indonesia.

Manuaba. (2013). Ilmu Kebidanan, Penyakit Kandungan. Jakarta: EGC.

Notoatmodjo, S. (2010). Metodologi Penelitian Kesehatan. Jakarta : Rineka Cipta.

Rafika. (2018). Efektivitas prenatal yoga terhadap pengurangan keluhan fisik pada ibu hamil trimester III. Jurnal Kesehatan Volume 9, Nomor 1, April 2018.

Retnaningsih, D. (2018). The effect of prenatal yoga on primigravida trimester II and III in studio qita yoga district south Semarang Indonesia. Jurnal Keperawatan, 9(1), 25-34.

Riwidikdo, H. (2008). Statistik kesehatan. Mitra Cendikia Press: Yogyakarta.

Sadock, B. (2015). Kaplan \& Sadock's Synopsis of psychiatry: Lippinott W Iliams And Wilkins, Philadelphia (USA).

Saifuddin. (2012). Metode Penelitian. Yogyakarta: Pustaka Pelajar.

Shodiqoh, E. (2014). Perbedaan tingkat kecemasan dalam menghadapi persalinan antara primigravida dan multigravida. Jurnal Berkala Epidemiologi. 2(1), 141-150.

Sugiyono. (2016). Metode penelitian kuantitatif kualitataif dan kombinasi (mixed methods). Bandung: Alfabeta.

Verbeek, T., R. Arjadi., J. J. Vendrik., $\mathrm{H}$. Burger and M. Y. Berger. (2015). Anxiety and depression during pregnancy in central America: A cross-sectional study among pregnant women in the developing country Nicaragua. BMC Psyhiatry.

Wahyuni. (2014). Pelaksanaan rujukan persalinan dan kendala yang dihadapi. Jurnal Ilmiah Rekam 
I Nyoman Suartha, dkk.: Gentle Yoga untuk Kecemasan Ibu Hamil Menghadapi Persalinan

Medis Dan Informatika

Kesehatan. INFOKES, Vol. 4 No 1 Februari 2014.

Walangadi, N. N. (2014). Hubungan pengetahuan ibu hamil

primigravida trimester III dengan tingkat kecemasan ibu menghadapi persalinandi poli KIA Puskesmas Tuminting. Jurnal Keperawatan, 2(2).

Zamriati, W. O. (2013). Faktor-faktor yang berhubungan dengan kecemasan ibu hamil menjelang persalinan di poli KIA PKM Tuminting. Jurnal Keperawatan, 1(1). 